\title{
Gênero, Sexualidade e Diversidade na Escola a partir da Perspectiva de Professores/as
}

\author{
Ana Flávia do Amaral Madureira ${ }^{1}$ \\ Curso de Graduação e Curso de Mestrado em Psicologia do Centro Universitário \\ de Brasilia, Brasilia, DF, Brasil \\ Ângela Uchoa Branco \\ Departamento de Psicologia Escolar e do Desenvolvimento da Universidade de Brasília, \\ Brasilia, DF, Brasil
}

\begin{abstract}
Resumo
A partir da perspectiva sociocultural, a pesquisa teve como objetivo analisar as concepções e crenças de professores/as do Ensino Fundamental, de $5^{\mathrm{a}}$ a $8^{\mathrm{a}}$ séries (atualmente $6^{\circ}$ a $9^{\circ}$ ano), da rede pública de ensino do Distrito Federal em relação às questões de gênero, sexualidade e diversidade. Em termos metodológicos, foram aplicados questionários na $1^{\text {a }}$ etapa, envolvendo 122 professores/as de sete escolas distintas. $\mathrm{Na} 2^{\mathrm{a}}$ etapa, participaram 10 professores/as de duas escolas que contribuíram na $1^{\mathrm{a}}$ etapa. Foram realizadas entrevistas individuais semiestruturadas e quatro reuniões de grupos focais em cada uma das duas escolas. Os resultados indicaram que, apesar da maioria dos/as participantes acreditar que a escola deve realizar um trabalho de educação sexual, há uma lacuna entre o que está previsto nos Parâmetros Curriculares Nacionais e o que ocorre de fato. Quando existe um trabalho de educação sexual, este corresponde a um trabalho limitado. Foi identificada uma lacuna, em termos de formação de professores, para lidar com as questões de gênero, sexualidade e diversidade na escola. Ao lidar com tais questões, os/as professores/as utilizam suas experiências e opiniões pessoais. Há um silêncio sobre a dimensão afetiva e prazerosa da sexualidade, o que parece distanciar o discurso dos/as professores/as do universo adolescente. Os resultados indicaram a necessidade de incorporação dos estudos de gênero e sexualidade nos cursos de Licenciatura, atividades de capacitação na área que contemplem discussões sobre as raízes histórico-culturais e as bases afetivas dos preconceitos e adoção de uma abordagem integrada de combate à homofobia e ao sexismo.
\end{abstract}

Palavras-chave: Gênero, sexualidade, diversidade na escola, preconceito, formação de professores/as.

\section{Gender, Sexuality and Diversity in Schools from Teachers' Perspective}

\begin{abstract}
From a sociocultural perspective, the present research analyzed $5^{\text {th }}$ to $8^{\text {th }}$ grade Middle School ("Ensino Fundamental" in Brazil) teachers' beliefs and conceptualizations about gender, sexuality and diver-

Endereço para correspondência: Centro Universitário de Brasília (UniCEUB), Curso de Psicologia, SEPN 707/907, Campus do UniCEUB, Asa Norte, Brasília, DF, Brasil 70790-075. E-mail: madureira.ana.flavia@, gmail.com

Este artigo foi elaborado a partir da tese de doutorado da primeira autora, sob a orientação da segunda autora, intitulada: Gênero, sexualidade e diversidade na escola: a construção de uma cultura democrática. Tese de doutorado defendida e aprovada em dezembro de 2007 no Instituto de Psicologia da Universidade de Brasília (UnB). As autoras gostariam de agradecer ao Conselho Nacional de Desenvolvimento Científico e Tecnológico $(\mathrm{CNPq})$ pelo suporte financeiro da pesquisa realizada, bem como às auxiliares de pesquisa Júlia Lagos Oliveira e Amanda de Oliveira Mota, na época alunas de graduação em Psicologia da UnB.
\end{abstract}


sity in Distrito Federal, Brazil. The methodology consisted of questionnaires during the first phase of the study, answered by 122 teachers from seven different public schools. In the second phase, 10 teachers from two schools that participated in the first phase participated of individual semi-structured interviews, as well as of four focal group sessions carried out in each one of the two schools. Results show that although the majority of participants agree that schools have to develop sexual educational programs, there is a gap between the public educational policy established by the National Curriculum Guidelines and what actually happens. When there is a sexual educational project, it seems to be very limited. The study revealed the absence of specific trainings for teachers to deal with gender, sexuality and diversity issues in schools. Teachers end up dealing with such issues using their own personal experiences and opinions. There is a silence about the dimensions of affection and pleasure of the sexuality domain, and this silence seems to distance teachers' discourse from the concerns of adolescents' world. Results show the necessity of including gender and sexuality studies as an important topic in teachers' graduation courses, as well as the implementation of specific trainings to promote discussions about the historical-cultural roots and the affective basis of prejudices, adopting an integrative perspective against homophobia and sexism.

Keywords: Gender, sexuality, diversity in schools, prejudice, teachers' training.

\section{Género, Sexualidad y Diversidad en Escuelas desde la Perspectiva de los/as Maestros/as}

\section{Resumen}

Desde el punto de vista sociocultural, la investigación tuvo como objetivo examinar las ideas y creencias de maestros/as de la escuela primaria de la red publica del Distrito Federal, Brasil, sobre las cuestiones de género, sexualidad y diversidad. En cuanto a la metodología, en la primera etapa fueron administrados cuestionarios, abarcando 122 maestros/as de siete escuelas distintas. En la segunda etapa, participaron 10 maestros/as de dos escuelas que ya habían contribuido a la primera etapa. Fueron realizadas entrevistas individuales semiestructuradas y cuatro sesiones de grupos focales en cada una de las dos escuelas. Los resultados indicaron que, aunque la mayoría de los participantes creen que la escuela debe llevar a cabo la educación sexual, hay una brecha entre lo que se prevé en el plan de estudios nacional y lo que realmente ocurre. Cuando existe un trabajo volcado a la educación sexual, este aun es limitado. Se identificó una brecha, en términos de formación, para hacer frente a cuestiones de género, sexualidad y diversidad en la escuela, en las cuales los/as maestros/as utilizan sus experiencias y opiniones personales. Hay un silencio acerca de la dimensión afectiva y agradable de la sexualidad. Esto parece distanciar el discurso de los/as maestros/as del universo de los adolescentes. Los resultados indicaron la necesidad de incorporar los estudios de género y sexualidad en los cursos de pregrado y actividades de capacitación que contemplen discusiones sobre las raíces histórico-culturales y afectivas de los prejuicios bajo un enfoque integrado para combatir la homofobia y el sexismo.

Palabras clave: Género, sexualidad, diversidad en las escuelas, prejuicio, capacitación de maestros/as.

O presente artigo apresenta os principais resultados de uma pesquisa ampla, que envolveu a articulação entre diferentes métodos de investigação. A pesquisa focalizou as concepções e crenças de professores/as da rede pública de ensino do Distrito Federal sobre questões de gênero, sexualidade e diversidade no contexto escolar. Considerando o papel fundamental das universidades públicas brasileiras na formação docente em todos os níveis educacionais, a pesquisa buscou construir conhecimentos que pudessem ser integrados à formação básica e continuada de professores/as, no que se refere ao desenvolvimento de competências para lidar de 
forma construtiva com a diversidade na escola e, de forma mais específica, com as questões de gênero e sexualidade. Para tanto, é importante partirmos das concepções e crenças de professores/as que estejam em contato direto com os/as alunos/as no cotidiano.

A base teórica da pesquisa está situada na psicologia sociocultural (Bruner, 1997; Cole, 1992; Madureira \& Branco, 2012a, 20012b; Ratner, 2002; Rogoff, 2003; Valsiner, 2007; Valsiner \& Rosa, 2007). A psicologia sociocultural corresponde a um campo de conhecimento híbrido, interdisciplinar, resultado de diálogos históricos estabelecidos entre a psicologia, a sociologia, a história, a antropologia, a linguística, entre outros. A psicologia sociocultural não seria um grupo teoricamente coerente, mas sim uma 'família' heterogênea (Valsiner \& Rosa, 2007). A psicologia sociocultural tem como um dos seus pressupostos centrais a gênese social do desenvolvimento psicológico individual. Além disso, considera os conceitos de cultura, mediação semiótica e experiência como ferramentas teórico-conceituais estruturantes do seu olhar teórico (Bruner, 1997; Madureira, 2012; Madureira \& Branco, 2012a, 2012b; Valsiner, 2007).

Consideramos que as experiências humanas sempre ocorrem em contextos culturais estruturados, perpassados por crenças, valores e práticas enraizadas historicamente e que canalizam, de diferentes formas, os processos de significação. Ao utilizarmos o termo canalização cultural destacamos o papel ativo das pessoas concretas nos processos de significação em relação ao mundo social em que estão inseridas e em relação a si mesmas (Madureira \& Branco, 2005). Portanto, a cultura constitui um conceito central que permite analisar o desenvolvimento humano em sua natureza simbólica. Afinal, o desenvolvimento psicológico individual não ocorre apenas em um ambiente físico e social, mas também simbólico, pois “. . . dar sentido ao mundo é uma força poderosa e inevitável na vida em sociedade" (Spink \& Medrado, 1999, p. 41).

Neste artigo, consideramos os preconceitos, como homofobia, sexismo, racismo, xenofobia, fundamentalismo religioso e tantos outros, enquanto fenômenos de fronteira. Os preconceitos são definidos como fronteiras simbólicas rígidas, construídas historicamente e com forte enraizamento afetivo, que acabam por se constituir em barreiras culturais entre grupos sociais e entre indivíduos (Madureira, 2007a, 2007b).

Nos diversos contextos culturais existem fronteiras simbólicas que delimitam, de forma semipermeável, as diferenças entre os indivíduos e grupos sociais. Quando tais fronteiras se tornam rígidas, não permeáveis, e passam a qualificar alguns grupos a partir da desqualificação constante e difusa de outros grupos, percebemos o preconceito em ação, ou seja, a discriminação. Quando estas fronteiras rígidas são alvos de transgressão, percebemos a violência e a intolerância, subjacentes às práticas discriminatórias, em relação aos/às supostos/as 'transgressores/ as' (Madureira \& Branco, 2012b). Para a manutenção das desigualdades sociais é fundamental que tais fronteiras sejam respeitadas, não importando o preço pago em termos de sofrimento psíquico. Afinal, sentir-se inferiorizado/a ou desqualificado/a por defeitos pré-supostos não é, certamente, uma experiência agradável.

Um estudo anterior (Madureira, 2000) evidenciou o quanto o preconceito e a discriminação em relação às identidades sexuais não hegemônicas acabam por se constituir em foco de sofrimento psíquico (ansiedade, depressão, culpa, vergonha...) por parte de sujeitos que apresentam orientações sexuais distintas da heterossexualidade. A pesquisa indicou a relevância de se considerar as estratégias pessoais e coletivas utilizadas pelos/as participantes no cotidiano para lidar com o preconceito e a discriminação em relação às identidades sexuais não hegemônicas. Tais estratégias são constitutivas da forma como estas pessoas vivenciam as suas experiências homoeróticas, suas relações sociais e consigo mesmas (Madureira, 2000; Madureira \& Branco, 2007).

Focalizar os preconceitos e as práticas discriminatórias em relação à diversidade sexual e de gênero no espaço escolar é uma forma de denunciar, por um lado, os processos de exclusão presentes em nossa sociedade. Por outro lado, é uma forma de indicar a existência de outras possibilidades de lidar com a diversidade humana, 
em sintonia com a construção de éticas multiculturais (Demo, 2005) e com a construção de uma cultura democrática em diferentes espaços da vida social, incluindo o espaço escolar.

O objetivo da pesquisa foi analisar as concepções e crenças de professores/as do Ensino Fundamental, de $5^{\mathrm{a}}$ a $8^{\mathrm{a}}$ séries (atualmente, $6^{\circ}$ a $9^{\circ}$ ano), da rede pública de ensino do Distrito Federal em relação às questões de gênero e sexualidade, com destaque para a questão da diversidade sexual e de gênero. Estas questões foram analisadas visando também obter subsídios para futuras propostas para a formação docente, inicial e continuada, que contemple as referidas questões.

\section{Método}

A pesquisa foi realizada em duas etapas distintas. Na primeira etapa, os/as professores/as de sete escolas públicas do Distrito Federal foram investigados/as mediante a aplicação de um questionário com questões fechadas e abertas (total: 122 questionários aplicados). Na segunda etapa, dez professores/as de duas escolas públicas selecionadas participaram de uma entrevista individual semiestruturada e quatro sessões de grupo focal em cada escola selecionada (seis professores/as de uma escola e quatro professoras de outra escola), totalizando oito sessões.

É importante destacar que buscamos integrar distintos métodos de investigação, em sintonia com o pluralismo metodológico defendido por Bauer, Gaskell e Allum (2002). Contudo, a investigação foi eminentemente qualitativa, pois todas as informações obtidas foram subordinadas a construção de uma rede interpretativa que possibilitou uma compreensão aprofundada dos significados atribuídos pelos/as participantes em relação às questões de gênero, sexualidade e diversidade no contexto escolar.

Os questionários, aplicados na primeira etapa da pesquisa, possibilitaram a construção de uma visão panorâmica sobre as concepções e crenças dos/as professores/as de sete escolas públicas em relação à temática em questão, possibilitando uma compreensão mais extensiva (ampla) sobre o fenômeno investigado. Por sua vez, as entrevistas e grupos focais, referentes à segunda etapa da pesquisa, permitiram a construção de uma compreensão intensiva (aprofundada) sobre o objeto de estudo. Cabe esclarecer que, em termos analíticos e interpretativos, privilegiou-se a análise qualitativa das informações construídas na segunda etapa da investigação. Nesse sentido, é pertinente afirmar que a pesquisa realizada correspondeu a uma investigação eminentemente qualitativa, apesar da utilização de um método quantitativo na primeira etapa da investigação.

A segunda etapa da pesquisa incluiu entrevistas individuais semiestruturadas e grupos focais de discussão, tendo em vista reunir informações sobre as concepções e crenças dos/as participantes sobre questões de gênero e sexualidade. Tanto as entrevistas individuais como as discussões em grupos focais apresentam vantagens e desvantagens (Gaskell, 2002). Portanto, ao integrá-las em uma mesma pesquisa procuramos compensar as desvantagens e potencializar as vantagens de cada uma. Por exemplo, as entrevistas individuais, por um lado, permitem a construção de análises mais aprofundadas sobre as concepções e crenças de cada participante de forma singular. Por outro lado, os grupos focais permitem identificar mais claramente os temas que tendem a suscitar posicionamentos convergentes, bem como aqueles que tendem a suscitar posicionamentos divergentes, ou mesmo antagônicos, no fluxo das interações interpessoais no momento das discussões.

É importante destacar que a entrevista não é um 'meio para acessarmos os "conteúdos intrapsíquicos do sujeito investigado, como se os mesmos já estivessem prontos dentro de sua cabeça. . . . O momento da entrevista consiste em um espaço dialógico" (Madureira \& Branco, 2001, p. 72). Ou seja, a entrevista caracteriza-se pela "troca de ideias e significados, em que várias realidades e percepções são exploradas e desenvolvidas" (Gaskell, 2002, p. 73) através de um processo coconstrutivo (Madureira \& Branco, 2001). Em síntese, defendemos que tanto as entrevistas individuais semiestruturadas como os grupos focais, enquanto métodos de pesquisa, correspondem a espaços dialógicos de coconstrução de significados por parte dos/as partici- 
pantes e do/a pesquisador/a sobre o objeto de estudo em foco.

\section{Participantes}

$\mathrm{Na}$ primeira etapa da pesquisa, participaram 122 professores/as de sete escolas públicas de Ensino Fundamental, de $5^{\mathrm{a}}$ a $8^{\mathrm{a}}$ séries (atual $6^{\circ}$ ao $9^{\circ}$ ano), do Distrito Federal $(n=122)$. Na segunda etapa, 10 professores/as - de duas escolas selecionadas: Escola A $(n=6)$, situada no Núcleo Bandeirante/DF e Escola B $(n=4)$, situada no Gama/DF - participaram das entrevistas individuais semiestruturadas. Os/as professores/ as entrevistados/as participaram, também, de quatro sessões de grupo focal realizadas em cada uma das escolas selecionadas.

\section{Procedimentos de Construção de Informações}

Inicialmente, foram aplicados 122 questionários entre professores/as de sete escolas públicas do Distrito Federal, distribuídas entre quatro Regionais de Ensino. Dentre as escolas que participaram nessa etapa, foram selecionadas duas escolas para a etapa seguinte, com base na receptividade e interesse demonstrados pela Direção e corpo docente.

$\mathrm{Na}$ segunda etapa, foram realizadas entrevistas individuais semiestruturadas com 10 professores/as das duas escolas selecionadas: Escola A $(n=6)$; Escola B $(n=4)$. Todos/as assinaram o Termo de Consentimento Livre e Esclarecido (TCLE). Cada entrevista teve uma duração aproximada de 120 minutos. O roteiro de entrevista foi estruturado a partir de 17 perguntas abertas. Para a realização das reuniões com os grupos focais, foi elaborado um roteiro flexível, visando nortear as atividades que seriam desenvolvidas com os/as professores/as.

Nos grupos focais foram desenvolvidas diversas atividades, como, por exemplo: (a) dinâmica de grupo voltada para a construção de histórias a partir de imagens extraídas de livros e revistas, seguida de discussão sobre as questões de gênero, sexualidade e diversidade a partir das histórias construídas pelos/as participantes; (b) apresentação de dez situações hipotéticas para que cada professor/a classificasse em uma escala de 1 a 10 o seu prazer ou o seu desconforto diante de cada situação, seguida da discussão sobre o espaço do prazer e do afeto nas discussões sobre sexualidade na escola; (c) discussão de casos concretos, envolvendo questões de sexualidade na escola, extraídos de uma revista que tem como público-alvo os/as profissionais de educação (Revista Nova Escola); dentre outras atividades.

Cabe mencionar que as entrevistas e os grupos focais foram gravados em áudio, com o consentimento dos/as professores/as.

\section{Resultados e Discussão}

No presente artigo, a discussão dos resultados foi organizada a partir dos seguintes eixos temáticos:

1. Gênero, sexualidade e educação sexual nas escolas; e,

2. Diversidade sexual e de gênero no contexto escolar: a tensão entre a reprodução de preconceitos e o respeito à diversidade.

Cabe destacar que, considerando os limites de espaço de um artigo, o que será apresentado corresponde, obviamente, a um recorte da pesquisa ampla realizada.

\section{Gênero, Sexualidade e Educação Sexual nas Escolas}

Observamos grande dificuldade na maioria dos/as professores/as em refletir sobre as questões de gênero. $O$ conceito de gênero parece distante de sua realidade, e continua restrito ao universo acadêmico. Enquanto as discussões acadêmicas sobre gênero alcançam um nível teórico-conceitual cada vez mais sofisticado, nas escolas a concepção de que as masculinidades e as feminilidades são construções culturais ainda é uma concepção distante. Portanto, pensar sobre questões de gênero de forma mais abstrata torna-se uma tarefa complicada para muitos/as professores/as. No entanto, os/as professores/as conseguiam refletir sobre gênero a partir de exemplos concretos, trazidos pela pesquisadora ou de sua autoria. Assim, é interessante que nas disciplinas 
ofertadas nos cursos de Licenciatura, bem como em atividades de formação continuada, as discussões tenham, como ponto de partida, exemplos concretos extraídos do cotidiano escolar.

Portanto, sugerimos que os aspectos teórico-conceituais, relativos ao campo de estudo interdisciplinar sobre as questões de gênero, sejam introduzidos após as discussões de exemplos concretos do cotidiano escolar. Dessa forma, acreditamos que as discussões sobre as questões de gênero seriam mais produtivas e significativas para os/as estudantes dos cursos de Licenciatura.

No que se refere às relações entre homens $\mathrm{e}$ mulheres na sociedade brasileira atual, 59,01\% dos/as participantes que responderam o questionário afirmam que a sociedade espera, sim, coisas diferentes de homens e mulheres. Nas entrevistas e nos grupos focais, em diferentes momentos, os/as participantes comentaram que, apesar das mudanças ocorridas nas últimas décadas, a sociedade brasileira continua machista. Cabe mencionar que a $2^{\text {a }}$ etapa da pesquisa contou com a participação de nove professoras e um professor. É importante destacar que o único professor que participou desta etapa é uma pessoa bastante sensibilizada em relação à relevância de discussões sobre as questões de gênero, apresentando uma visão crítica em relação ao machismo ainda vigente em nossa sociedade.

Em linhas gerais, os/as participantes da $2^{\mathrm{a}}$ etapa da investigação acreditam que não houve uma mudança efetiva nas relações de gênero na esfera privada. As mulheres estão submetidas a uma dupla, tripla jornada de trabalho, sentida na 'pele' pelas professoras. Mesmo quando as mulheres têm uma inserção profissional, como é o caso das professoras que participaram da pesquisa, as mesmas têm que lidar com as expectativas sociais tradicionais relativas aos 'papéis' de mãe, esposa e dona de casa.

Contudo, esta percepção não implica, necessariamente, em um questionamento crítico sobre as desigualdades nas relações de gênero na esfera privada/familiar. Algumas professoras parecem lançar mão de uma visão essencialista sobre as questões de gênero, criticada por diversos/ as autores/as na contemporaneidade (Hall, 1998; Louro, 1998, 2004; Moreira \& Câmara, 2008;
Woodward, 2000). Por exemplo, algumas professoras expressaram concepções sobre a masculinidade do estilo: 'os homens são assim' (não dividem as tarefas domésticas). Percebemos o quanto o essencialismo cumpre um papel estratégico na manutenção das relações de gênero desiguais, na medida em que desloca o problema - sobrecarga de trabalho por parte das mulheres - para um campo insolúvel: a suposta 'natureza' masculina. Tal 'argumento' foi utilizado, explicitamente, em uma das entrevistas realizadas (entrevista 6 - categoria analítica: gênero, voltada à análise das concepções e crenças dos/as participantes sobre as questões de gênero).

Cabe, então, questionarmos: se as relações entre homens e mulheres estão estruturadas a partir de uma suposta 'natureza' masculina e uma suposta 'natureza' feminina, como tais relações podem ser transformadas visando à promoção de relações igualitárias? A resposta óbvia seria: não podem ser mudadas. Eis um ponto nevrálgico na promoção da igualdade de gênero, é necessário um questionamento radical desta visão essencialista sobre homens e mulheres. Certamente, há diferenças biológicas entre homens e mulheres. Entretanto, o 'argumento' essencialista amplifica as diferenças biológicas e, principalmente, utiliza a Biologia para justificar as desigualdades sociais entre homens e mulheres.

Argumentos pseudocientíficos, ancorados na Biologia, têm sido utilizados, frequentemente, desde o século XIX, para justificar uma série de desigualdades entre grupos sociais: entre homens e mulheres, entre brancos e negros, entre pobres e ricos, como bem demonstrou Stephen Jay Gould (1991), em sua obra "A Falsa Medida do Homem". Portanto, é de suma importância na formação de educadores/as a promoção de discussões críticas sobre argumentos voltados para legitimação de desigualdades sociais, a partir de uma apropriação equivocada e de generalizações distorcidas de conhecimentos produzidos pela Biologia. No combate às diversas formas de preconceito, tais discussões assumem uma relevância ainda maior quando consideramos o espaço de poder ocupado pelos discursos científicos na contemporaneidade. $\mathrm{O}$ que acaba por conferir um 'verniz de cientificidade' a argumentos que, 
na realidade, estão fundamentados em concepções preconceituosas.

Ainda em relação às questões de gênero, foi identificado no discurso dos/as professores/as um descompasso entre a promoção da igualdade entre homens e mulheres na esfera profissional (mundo público) e na esfera dos relacionamentos amorosos, no casamento e nas relações familiares (mundo privado). A igualdade na esfera profissional é defendida por todos/as os/as professores/as que participaram das entrevistas e grupos focais. O que, por sinal, faz todo sentido, já que a grande maioria dos/as participantes da $2^{\mathrm{a}}$ etapa da investigação é formada por mulheres profissionais. Entretanto, quando saímos da esfera profissional e focalizamos as relações entre homens e mulheres na esfera privada, percebemos a existência de concepções e crenças divergentes. Por exemplo, uma professora afirmou que:

Eu acho que muita igualdade, também, não faz bem não, sabe? . . porque já é tudo, tudo direitos iguais, tanto no serviço, no trabalho, a procura é essa, né? Aí, você tem uma, assim, uma igualdade, uma liberdade sexual [ênfase na fala da professora], entendeu? Uma liberdade sexual que eu, assim, às vezes eu acho que não vale a pena, sabe? Essa professora defende que homens e mulheres não devem ter direitos iguais na esfera da sexualidade. Tal igualdade implicaria, na percepção dela, em uma liberdade sexual para as mulheres que não seria desejável, na medida em que ela acredita que: "a mulher tem que se preservar mais, se resguardar". Liberdade sexual para as mulheres é interpretada, por ela, como sinônimo de promiscuidade. Nesta entrevista ficou evidente que a expectativa social de que as mulheres sejam mais 'recatadas' no exercício da sexualidade - ou seja, mais 'passivas' (Parker, 1991) - não pode ser interpretada a partir de explicações simplistas, que circulam no cotidiano, do estilo: "é a opressão masculina". As próprias mulheres ocupam, frequentemente, uma posição estratégica no controle social sobre o corpo e a sexualidade feminina, pois vigiam, avaliam e julgam o comportamento sexual de outras mulheres. Afinal, a fofoca sobre a vida sexual de outras mulheres é um eficiente mecanismo de controle informal sobre o corpo e a sexualidade feminina (Madureira, 2007a, 2012).

Isso significa que sempre devemos estar atentos/as em relação às concepções, crenças, valores e práticas culturais de homens e mulheres que acabam por sustentar relações de gênero desiguais. Apesar de reconhecermos que, historicamente, as relações de gênero têm beneficiado os homens (Bourdieu, 2005), tais relações são organizadas e sustentadas por homens e mulheres.

Outros exemplos podem ser extraídos dos resultados obtidos na $3^{\mathrm{a}}$ reunião de discussão no grupo focal da Escola B. Nessa reunião, uma das professoras afirmou que:

hoje, a mulher [ênfase na fala da professora], ela se tornou alvo muito fácil [ênfase na fala da professora]. Hoje o aluno ... quando eu falo o aluno é o homem, ele não tem o prazer da conquista mais. Na verdade, é ela que se oferece pra ele.

Diante desta constatação, a professora aconselha que

mulher tem que ser dificil, porque mulher muito fácil, nenhum homem se interessa [ênfase na fala da professora]. Mas não é no sentido de não ter nada [ênfase na fala da professora] com ninguém, mas no sentido de qualquer um pegar, qualquer um tocar.

Neste grupo focal, inclusive, uma temática recorrente foi a questão da desvalorização da mulher na atualidade, sendo que tal desvalorização é associada, em diferentes momentos, à atitude das próprias mulheres.

Constatamos, portanto, a reprodução de significados culturais arcaicos sobre a feminilidade que expressam uma visão pejorativa sobre a sexualidade das mulheres. O desenvolvimento de análises críticas sobre as raízes históricas de tais significados culturais arcaicos acerca da feminilidade é de suma importância. Por exemplo, em outro estudo (Madureira, 2012), foram problematizadas as raízes históricas da visão pejorativa sobre o corpo e a sexualidade das mulheres a partir da análise de alguns elementos presentes na iconografia cristã medieval. Período histórico fortemente marcado pela misoginia, pela associação entre feminilidade e forças demoníacas. 
Nesse sentido, as mulheres são consideradas 'perigosas', culpadas por 'desencaminharem' os homens e, portanto, deveriam ser alvo do mais estrito controle social, a fim de que seu "potencial pecador intrínseco" não se manifestasse.

De forma implícita, seriam as alunas "assanhadas" que provocariam a sexualidade dos alunos (nunca o inverso). Se, por um lado, há o reconhecimento por parte das professoras que os alunos rotulam de forma pejorativa as alunas consideradas "assanhadas"; por outro lado, o rótulo em si não é objeto de questionamento. São as alunas que recebem conselhos para mudar de atitude e passarem 'a se valorizar'. Curiosamente, a valorização da mulher passa pela valorização do seu corpo, enquanto que no caso dos homens tal associação parece ser bem incomum. Mais do que isso: é incompatível com a lógica cultural subjacente à construção da masculinidade hegemônica, marcada pelo elogio à precocidade e diversidade de experiências sexuais, ao comportamento ativo na esfera da sexualidade, à virilidade (Bourdieu, 2005; Junqueira, 2009; Parker, 1991).

De diferentes formas, significados arcaicos sobre a feminilidade e a masculinidade - que remontam à sociedade brasileira no período colonial, como analisado por Parker (1991) - são reatualizados no cotidiano das escolas. Ou seja, a dicotomia: (a) masculinidade - atividade - domínio do espaço público versus (b) feminilidade - passividade - domínio do espaço privado, continua bem viva na atualidade. Com uma curiosa diferença: as mulheres, da classe média e da classe alta da sociedade, conquistaram o espaço público do trabalho, mas continuam sendo alvo de constantes avaliações morais por parte de homens e de outras mulheres.

As formas como homens e mulheres vivenciam e dão sentido à sua sexualidade é mediada, de forma importante, pelas crenças, valores e práticas culturais orientados pelas questões de gênero (Blackwood, 2000). Em termos de formação de professores/as, é necessário considerar a dimensão motivacional e integrarmos sexualidade e gênero. É preciso também abordar a sexualidade evitando a reprodução de estereótipos de gênero.

O tema em foco poderá ser trabalhado de acordo com algumas das propostas de educação sexual construídas pelos/as professores/as que participaram da pesquisa. $\mathrm{O}$ trabalho deveria ser desenvolvido a partir de uma metodologia participativa que integre a apresentação de informações e a realização de discussões com os/as alunos/as. Para tanto, foi sugerida pelos/as participantes da pesquisa a utilização de recursos variados, como filmes, debates, jogos, dramatizações, análise crítica de piadas e programas televisivos, dentre outros. Para a concretização do trabalho idealizado, os/as participantes enfatizaram a necessidade de: (a) capacitação profissional; (b) estabelecimento de parcerias entre a escola e outras instituições; (c) envolvimento da família e da comunidade.

Cabe mencionar que alguns temas - como diversidade sexual e preconceitos - foram contemplados nos objetivos delineados por alguns(mas) participantes, mas não por todos/as. Mas não são apenas convergências e divergências que cercam o tema da sexualidade na escola, há muitos silêncios e 'não ditos' também. Talvez, o maior silêncio seja em torno da dimensão afetiva e, principalmente, em torno da dimensão prazerosa da sexualidade. Falar em prazer, ao se trabalhar com o tema sexualidade na escola, parece ser algo bastante problemático. Após a realização da dinâmica "prazer versus desconforto" - recurso utilizado para estimular a discussão entre os/as professores/as sobre a afetividade e os prazeres na esfera da sexualidade (grupos focais, $3^{\text {a }}$ reunião) - um dos professores da Escola A (professor de Ciências) afirmou que:

Porque eu tenho receio de até que ponto eu posso estar falando, até que ponto a família vai permitir que o filho dela possa ouvir aquilo [ênfase na fala do professor]. Porque isso foge do conteúdo, foge do que a Secretaria [de Educação] pede [ênfase na fala do professor] que eu faça. Entendeu? Então, existe essa dificuldade de tá falando realmente.

Diante de tais obstáculos, parece que a melhor solução é o silêncio diante desta questão ou a adoção de uma abordagem superficial. Trabalhar com a questão dos prazeres sexuais parece ser bastante incômodo, representando uma ame- 
aça no contexto de uma instituição que lida, no seu cotidiano, com a expectativa social ambígua de ser, por um lado, 'assexuada' e, por outro lado, incentivar a heterossexualidade (Louro, 1998). É importante destacar, também, que nas discussões nos grupos focais em ambas as escolas, emergiu a imagem da sexualidade como um "terreno perigoso", "escorregadio". Parece que a abordagem mais segura no contexto escolar tem como foco as potenciais consequências negativas do exercício da sexualidade na adolescência: gravidez precoce e DSTs (doenças sexualmente transmissíveis)/AIDS. Em outras palavras, a ênfase recai nos riscos e nos perigos relacionados ao exercício da sexualidade. Outras dimensões da sexualidade simplesmente não são abordadas, notadamente a questão do prazer e da afetividade. Para alguns(mas) participantes, parece, inclusive, que o uso de preservativos nas relações sexuais assume uma importância secundária diante da expectativa social (implícita) de que os/as adolescentes não tenham uma vida sexual ativa.

Esse é um aspecto central constatado na pesquisa realizada: o silêncio, intencional ou não, sobre a afetividade e, principalmente, sobre o prazer nas discussões sobre sexualidade na escola, parece ser um dos elementos que distanciam o discurso dos/as professores/as do universo de preocupações e questionamentos dos/as adolescentes.

Não seria exagero supor que este silêncio acabe por se constituir em um dos obstáculos para o estabelecimento de um espaço dialógico, entre alunos/as e professores/as, favorável ao desenvolvimento da autonomia e da responsabilidade em relação à sexualidade por parte dos/ as adolescentes. Isso acaba por comprometer o objetivo geral do trabalho de educação sexual na escola, conforme estabelecido nos Parâmetros Curriculares Nacionais: $5^{\mathrm{a}}$ a $8^{\mathrm{a}}$ séries (Secretaria de Educação Fundamental, 1998, p. 311): "A finalidade do trabalho de Orientação sexual é contribuir para que os alunos possam desenvolver e exercer sua sexualidade com prazer e responsabilidade ....". Em síntese, o trabalho de educação sexual na escola deve buscar estimular entre os/as alunos/as o desenvolvimento de uma relação autônoma, responsável e prazerosa com a própria sexualidade.

De acordo com os Parâmetros Curriculares Nacionais: $5^{\mathrm{a}}$ a $8^{\mathrm{a}}$ séries (Secretaria de Educação Fundamental, 1998), a educação sexual no contexto escolar deve ser realizada de forma interdisciplinar, de modo a contemplar os seguintes eixos norteadores: (a) corpo: matriz da sexualidade; (b) relações de gênero; e (c) prevenção das doenças sexualmente transmissíveis/Aids. Além disso, deve estimular a construção de um pensamento crítico em relação aos estereótipos e discriminações no campo da sexualidade, conforme é expresso no trecho a seguir:

O trabalho com Orientação Sexual supõe refletir sobre e se contrapor aos estereótipos de gênero, raça, nacionalidade, cultura e classe social ligados à sexualidade. Implica, portanto, colocar-se contra as discriminações associadas a expressões da sexualidade, como a atração homo ou bissexual, e aos profissionais do sexo. (Secretaria de Educação Fundamental, 1998, p. 316)

Os Parâmetros Curriculares Nacionais (Secretaria de Educação Fundamental, 1998) apresentam, portanto, diretrizes para o trabalho de educação sexual no contexto escolar distantes do 'porto seguro' do discurso biomédico, circunscrito aos aspectos meramente biológicos da sexualidade. Diretrizes que, infelizmente, ainda parecem distantes da realidade cotidiana de muitas escolas.

\section{Diversidade Sexual e de Gênero no Contexto Escolar: A Tensão entre a Reprodução de Preconceitos e o Respeito à Diversidade}

... Tanto homens como mulheres que apresentam uma identidade sexual não-hegemônica se constituíram enquanto sujeitos em contextos socioculturais marcados, em diferentes graus, pela homofobia, por uma concepção de normalidade que exclui outras possibilidades de vivência da própria sexualidade. (Madureira \& Branco, 2007, p. 87)

Como discutido no tópico anterior, a sexualidade não está do lado de fora dos muros da escola. Da mesma forma, não são externos ao 
espaço escolar os preconceitos em relação àqueles e àquelas que não correspondem aos padrões hegemônicos em termos de orientação afetivo-sexual e/ou identidade de gênero. Situações em que um aluno ou uma aluna são alvo de gozação por parte dos/as colegas, por apresentarem comportamentos considerados 'culturalmente' não adequados em relação ao seu sexo, são situações comuns no cotidiano escolar. Muitos/as professores/as que participaram da $1^{\mathrm{a}}$ etapa da pesquisa $(77,87 \%)$ disseram já ter presenciado situações desse tipo. Da mesma forma, os/as professores/ as que participaram da $2^{\mathrm{a}}$ etapa da investigação já presenciaram, também, várias situações dessa natureza. Qual o posicionamento deles/as diante dessas situações?

A partir dos resultados obtidos nos questionários, a maioria dos/as professores/as destaca a importância do respeito às "opções sexuais" individuais (o termo orientação sexual é distante do discurso dos/as professores/as). Contudo, no extremo oposto, há um grupo minoritário de professores/as que nutre concepções e crenças homofóbicas na direção da 'cura' ou 'prevenção' da homossexualidade, seja através da 'intervenção' de especialistas $(8,20 \%)$ ou através de um trabalho de 'orientação moral' (4,92\%). Neste grupo minoritário, há, também, professores/as que associam a homossexualidade à influência de 'espíritos malignos' e defendem a 'cura' através da 'intervenção' divina. Tais concepções homofóbicas apareceram nas respostas de alguns/ mas professores/as evangélicos/as.

É importante deixar claro que o posicionamento expresso anteriormente não é unânime entre os/as participantes evangélicos/as que responderam o questionário. Entretanto, nos questionários respondidos pelos/as professores/as na primeira etapa da pesquisa, é importante notar que entre as respostas que nutrem uma visão explicitamente pejorativa sobre a homossexualidade, a maioria provém do grupo de professores/ as evangélicos/as. Obviamente, seria uma interpretação simplista defender a existência de uma relação direta e linear entre religião e concepções e crenças homofóbicas. Por outro lado, não devemos ignorar que a religião é, sim, um aspecto importante nas pesquisas sobre a homofobia e sobre a construção de estratégias de promoção do respeito à diversidade sexual e de gênero na escola.

Como há uma estreita relação entre os preconceitos e o sistema de valores pessoais (Madureira, 2012; Madureira \& Branco, 2012a, 2012b), aqueles indivíduos que, por diversos motivos, estabeleceram uma relação rígida com os seus valores religiosos tendem a apresentar atitudes homofóbicas. É importante ter em mente, entretanto, que a questão em foco não corresponde aos valores religiosos em si, mas a relação que as pessoas estabelecem com os seus valores religiosos. Relação que pode se configurar de forma bastante rígida, como é expresso nas atitudes características do fundamentalismo religioso, que tende a conduzir a práticas de intolerância em relação a diversos grupos sociais.

A $2^{\mathrm{a}}$ etapa da pesquisa não contou com a participação de nenhum/a professor/a evangélico/a. Participaram desta etapa seis professores/as católicos/as, três professoras espíritas e uma professora que não tem religião. Duas professoras católicas que destacaram - na situação de entrevista ou no grupo focal - a importância das suas crenças religiosas em suas vidas, afirmaram que têm dificuldades de lidar com situações em que um aluno ou uma aluna são alvo de gozação por parte dos/as colegas por apresentarem comportamentos considerados 'culturalmente' não adequados em relação ao seu sexo (entrevistas 1 e 10). Por um lado, ambas defendem a importância do respeito às diferenças individuais; por outro, afirmam que se sentem desconfortáveis diante dessas situações, que envolvem lidar com um aluno considerado "efeminado" ou uma aluna considerada "masculinizada" em sala de aula.

Há, portanto, um conflito entre valores distintos: (a) respeito às diferenças individuais versus (b) respeito às próprias crenças religiosas. Todavia, cabe mencionar que ambas demonstraram interesse em participar da pesquisa e acreditam na importância de se discutir questões relativas à sexualidade na escola. Em outras palavras, não são profissionais fechadas ao debate, mas que se sentem desconfortáveis para lidar com situações desse tipo, ou seja, lidar no seu cotidiano profissional com alunos/as que são, ou que são socialmente vistos/as como, homossexuais. 
Nesse momento, é importante retomarmos a definição de preconceitos adotada nesta pesquisa: preconceitos correspondem a fronteiras simbólicas rígidas, construídas historicamente e com forte enraizamento afetivo que acabam por se constituir em barreiras culturais entre grupos sociais e entre indivíduos (Madureira, 2007a, 2007b). Portanto, um elemento estruturante das diversas formas de preconceito (incluindo a homofobia) corresponde ao seu enraizamento afetivo. De forma mais precisa, sentimentos desconfortáveis - como medo, ansiedade, insegurança e, em casos extremos, ódio - emergem quando determinadas fronteiras simbólicas são transgredidas. Subjacente à homofobia, há a expectativa de que todos/as sejam heterossexuais. Como tal expectativa é realisticamente inviável, há a expectativa, então, de que 'pelo menos' aqueles/ as que não são heterossexuais (ou que não correspondam à masculinidade e à feminilidade hegemônicas) fiquem o mais longe possível dos olhos. Como afirma Pierre Bourdieu (2005, pp. 143-144):

A forma particular de dominação simbólica de que são vítimas os homossexuais, marcados por um estigma que, à diferença da cor da pele ou da feminilidade, pode ser ocultado (ou exibido) ... A opressão como forma de "invisibilização" traduz uma recusa à existência legítima, pública, isto é conhecida e reconhecida, sobretudo pelo Direito, e por uma estigmatização que só aparece de forma realmente declarada quando o movimento reivindica a visibilidade. Alega-se, então, explicitamente, a "discrição" ou a dissimulação que ele é ordinariamente obrigado a se impor.

A presença de um aluno ou de uma aluna em sala de aula que é - ou é socialmente percebido/a como - homossexual, tende a despertar sentimentos desconfortáveis por parte dos/as colegas e dos/as professores/as. Esses sentimentos desconfortáveis são um 'convite para ação', ou seja, tendem a acionar mecanismos de normatização do/a suposto/a transgressor/a. E, assim, diversas práticas discriminatórias ganham forma ('gozações', brincadeiras maldosas e, em casos extremos, agressão física).
Nesse sentido, uma importante implicação em termos de formação, inicial e continuada, de professores/as no que tange à construção de estratégias de superação da homofobia e do sexismo, ambos fortemente vinculados (Andersen, 2000; Junqueira, 2009; Madureira, 2007a; Welzer-Lang, 2001), corresponde à abertura de um espaço de discussão e problematização sobre as bases afetivas dos preconceitos (Madureira, 2007a, 2007b, 2012; Madureira \& Branco, 2012a, 2012b). Outra importante implicação é a realização de discussões sobre as raízes histórico-culturais dos preconceitos. Por exemplo, ao focalizar questões relativas ao machismo no contexto escolar, é de fundamental importância analisar as raízes histórico-culturais dessa forma de preconceito na nossa sociedade, incluindo o período do Brasil colonial (Vainfas, 2010). Em relação às diversas formas de preconceito, é de suma importância que os atores sociais inseridos nas comunidades escolares percebam claramente que estão diante de questões que apresentam uma gênese cultural e não diante de 'fatos da natureza', da ordem do imutável, impassíveis diante das intervenções humanas.

Em síntese, é fundamental estimular a reflexão e a discussão sobre as raízes histórico-culturais e efetivas das diferentes formas de preconceito nas escolas (Madureira \& Branco, 2012b). Afinal, a 'eficácia excludente' dos preconceitos está ancorada, também, no fato de que normalmente as pessoas não falam sobre eles e, assim, continuam sendo reproduzidos sem maiores questionamentos.

Os preconceitos não são, portanto, 'invenções individuais'. Cabe analisarmos criticamente a forma como, ao longo da história, foram sendo construídas categorias para delimitar fronteiras simbólicas e traçar hierarquias entre grupos sociais. Tais categorias orientam a forma como as pessoas organizam, em termos cognitivos e afetivos, a sua compreensão sobre $o$ mundo social em que estão inseridas e sobre si mesmas. Aqueles/as que não se comportam de acordo com as normas estabelecidas são, muitas vezes, vistos/as como pessoas 'não confiáveis', que podem surpreender a qualquer instante com atitudes 'imorais imprevisíveis', o que 'justifi- 
caria' seu isolamento e a discriminação (Moreira \& Câmara, 2008).

$\mathrm{Na}$ construção de estratégias que promovam o respeito à diversidade sexual e de gênero, um ponto fundamental corresponde à construção coletiva no espaço escolar de um equilíbrio entre o respeito às crenças religiosas de cada indivíduo, essencial em qualquer regime democrático, e o respeito ao caráter laico do Estado Democrático Brasileiro. Em outras palavras, cada pessoa tem o direito legítimo de viver de acordo com as suas crenças religiosas e expressá-las na sua vida cotidiana. Contudo, as instituições - especialmente as instituições públicas, incluindo as escolas - não devem fomentar práticas discriminatórias, quaisquer que sejam, baseadas em princípios religiosos (Caputo, 2008; Madureira \& Branco, 2012b). Garantir que as práticas cotidianas no interior das instituições públicas sejam realmente orientadas pelo caráter laico do Estado Democrático Brasileiro é um sério desafio a ser enfrentado. Afinal, a homofobia não diz respeito 'apenas a uma minoria'. Trata-se de um problema de toda sociedade democrática. Como afirma Borrillo (2009),

A homofobia constitui uma ameaça aos valores democráticos de compreensão e respeito pelo outro, pois promove a desigualdade entre os indivíduos em função de seus desejos, encoraja a rigidez dos gêneros e favorece a hostilidade ao outro. . . Na verdade, a homofobia é não só uma violência contra os homossexuais, mas igualmente uma agressão aos valores fundadores da democracia. (p. 43)

Por mais complexa que seja essa questão, ainda mais em um país onde as fronteiras entre o público e o privado são frequentemente transpostas (DaMatta, 1987), devemos enfrentar o desafio envolvido na construção deste delicado equilíbrio, conforme mencionado anteriormente. Afinal, este é um desafio de suma importância no que tange à construção de 'pontes' que viabilizem a implementação, nas salas de aula, das diretrizes previstas nas políticas públicas brasileiras atuais na área de gênero e sexualidade. Além disso, é um passo fundamental na constru- ção de uma cultura democrática na escola e, em um sentido mais amplo, um passo importante na consolidação da democracia em nosso país.

$\mathrm{Na}$ mesma linha dos resultados obtidos na ampla pesquisa promovida pelo escritório da Organização das Nações Unidas para a Educação, a Ciência e a Cultura (UNESCO) no Brasil e coordenada por Castro, Abramoway e Silva (2004), a presente investigação identificou um posicionamento crítico por parte da maioria dos/as professores/as em relação às diversas formas de preconceito. Por exemplo, entre os/as professores/ as que participaram da $2^{\mathrm{a}}$ etapa da investigação, todos/as acreditam que a escola deve combater os preconceitos. Diante de concepções preconceituosas e atitudes discriminatórias contra aqueles/as que são, ou que são considerados/as, homossexuais, a estratégia utilizada pela maioria é discutir com os/as alunos/as a importância do respeito às diferenças individuais e a importância do combate às diversas formas de preconceito. Todavia, de um modo geral, os/as professores/ as não discutem com os/as alunos/as a questão específica do preconceito contra as pessoas que apresentam orientações afetivo-sexuais distintas da heterossexualidade (homofobia).

Segundo a percepção dos/as professores/as, as alunas são mais "diplomáticas" e "maleáveis" em relação a esta questão, ou seja, a homofobia é mais explícita e apresenta raízes mais profundas entre os alunos (Castro et al., 2004). Alguns/mas professores/as mencionaram, inclusive, casos de alunos que associam a ideia de punição física com a ideia de 'cura' da homossexualidade: "bater para curar". Segundo eles/as, os alunos trazem, muitas vezes, esta concepção de casa, pois ouviram do pai afirmações desta natureza.

A questão do respeito à diversidade sexual $\mathrm{e}$ de gênero é, certamente, uma temática complexa que envolve questões polêmicas, preconceitos seculares, afetivamente arraigados. Se, por um lado, há uma série de avanços significativos no mundo contemporâneo em prol dos direitos humanos da população LGBTTT (Lésbicas, Gays, Bissexuais, Travestis, Transexuais e Transgêneros). No Brasil, podemos citar como exemplos nessa direção: a elaboração do Programa Brasil 
sem Homofobia: Programa de Combate à Violência e à Discriminação contra GLTB e de Promoção da Cidadania Homossexual (Conselho Nacional de Combate à Discriminação \& Ministério da Saúde, 2004), que busca articular as ações de diversos Ministérios no combate à homofobia, bem como o reconhecimento jurídico das uniões homoafetivas por parte do Supremo Tribunal Federal em 2011.

Por outro lado, até mesmo com uma reação a este avanço, há tenazes resistências por parte de diversos grupos conservadores, no Brasil e em outros países, que sentem este avanço como uma ameaça à ordem social, jurídica, política e moral (Fone, 2000). A sociedade é um terreno político perpassado pela tensão entre a manutenção do status quo e a promoção de mudanças. A escola - enquanto instituição social que cumpre um papel estratégico na formação das novas gerações na contemporaneidade - é perpassada, também, por esta tensão.

\section{Conclusão}

A psicologia sociocultural, ao enfatizar a importância dos contextos culturais no estudo do desenvolvimento humano, procura estabelecer 'pontes' também com outros campos de investigação científica, para além da ciência psicológica, mediante o estabelecimento de diálogos interdisciplinares. Tais diálogos são primordiais, considerando a natureza multifacetada dos preconceitos e das práticas discriminatórias. Cabe destacar que, além dos pressupostos teóricos que estão na base e nas entrelinhas da pesquisa realizada, a mesma foi orientada também por um compromisso ético: o conhecimento produzido nas pesquisas acadêmicas deve, em alguma medida, contribuir na concretização de uma sociedade justa e democrática. Portanto, o conhecimento deve ser instrumento de denúncia das concepções preconceituosas e das práticas discriminatórias que estigmatizam e excluem certos grupos sociais, enquanto conferem uma posição de superioridade e pretensa 'normalidade' a outros grupos que ocupam posições hegemônicas na sociedade (em termos de classe social, gênero, orientação sexual, etnia, etc.).
Apesar da lacuna existente na formação de professores/as na área de gênero, sexualidade e diversidade, identificamos na pesquisa o desejo, por parte da maioria dos/as participantes, de capacitação na área, de contribuição com o combate às diversas formas de preconceito, de promoção do respeito à diversidade, seja pela ênfase no respeito às diferenças individuais, seja pelo reconhecimento de que somos todos/ as seres humanos. Tal reconhecimento, nas relações interpessoais, é o primeiro passo na construção de vínculos empáticos. Nesse sentido, a empatia, em termos metafóricos, pode funcionar como um 'antídoto' contra a intolerância e à discriminação.

É necessário, portanto, investirmos na ampliação dos espaços institucionais e relacionais destinados a trabalhar as emoções, crenças e valores no sentido da consolidação de práticas reflexivas em sintonia com a construção de uma cultura democrática de valorização da diversidade no contexto escolar.

Ao longo da pesquisa, verificou-se a importância do estabelecimento de uma parceria entre pesquisadores/as e professores/as do Ensino Fundamental. Ambos/as têm muito a ganhar com a construção de um 'espaço dialógico', marcado pela cooperação. Em um sentido mais amplo, tanto a universidade como a escola podem se beneficiar com o estabelecimento de uma parceria mais próxima e consistente. Nesse sentido, a consolidação da parceria entre universidade e escola é um passo importante na direção "de tornar a escola um espaço democrático de desenvolvimento humano ..." (Guzzo, 2003, p. 35). Um espaço democrático de desenvolvimento para todos/as que fazem parte da comunidade escolar.

É de suma importância explicitar e combater os mecanismos excludentes que se fazem presentes, muitas vezes de forma sutil, no interior do espaço escolar. A partir da consciência em relação a tais mecanismos será possível, então, delinearmos diversas estratégias de intervenção. Para trabalhar questões relativas à sexualidade no contexto escolar, cabe retomar algumas das sugestões apresentadas pelos/as participantes da pesquisa realizada, como, por exemplo: desen- 
volver atividades com a utilização de recursos variados, como filmes, jogos, dramatizações, análise crítica de piadas e programas televisivos, debates, etc. Utilizar diferentes linguagens enquanto ferramentas educacionais, e não apenas a linguagem verbal, parece se constituir em um caminho fértil na promoção de reflexões críticas sobre os mecanismos excludentes que perpassam o espaço escolar.

Compromisso social, senso crítico e criatividade são fundamentais no processo de elaboração e implementação de estratégias de intervenção que promovam a autonomia dos sujeitos envolvidos nos processos educativos. Estratégias de intervenção que colaborem, efetivamente, na construção de uma sociedade democrática que tenha como um dos seus pilares a valorização da diversidade, do poder da criação e da reinvenção do mundo em que vivemos e da reinvenção de cada um/a de nós.

\section{Referências}

Andersen, M. L. (2000). Thinking about women: Sociological perspectives on sex and gender. Needham Heights, MA: Allyn and Bacon.

Bauer, M. W., Gaskell, G., \& Allum, N. C. (2002). Qualidade, quantidade e interesses do conhecimento: Evitando confusões. In M. W. Bauer \& G. Gaskell (Eds.), Pesquisa qualitativa com texto, imagem e som: Um manual prático (pp. 17-36). Petrópolis, RJ: Vozes.

Blackwood, E. (2000). Culture and women's sexualities. Journal of Social Issues, 56(2), 223-238. doi:10.1111/0022-4537.00162

Borrillo, D. (2009). A homofobia. In T. Lionço \& D. Diniz (Eds.), Homofobia \& Educação: Um desafio ao silêncio (pp. 15-46). Brasília, DF: LetrasLivres.

Bourdieu, P. (2005). A dominação masculina. Rio de Janeiro, RJ: Bertrand Brasil.

Bruner, J. S. (1997). Atos de significação. Porto Alegre, RS: Artes Médicas.

Caputo, S. G. (2008). Ogan, adósu, oje, egbonmi e ekedi: O candomblé também está na escola. Mas como? In A. F. Moreira \& V. M. Candau (Eds.), Multiculturalismo: Diferenças culturais e práticas pedagógicas (pp. 149-181). Petrópolis, RJ: Vozes.
Castro, M. G., Abramovay, M., \& Silva, L. B. (2004). Juventudes e sexualidade. Brasília, DF: Organização das Nações Unidas para a Educação, a Ciência e a Cultura Brasil.

Cole, M. (1992). Culture in development. In M. H. Bornstein \& M. E. Lamb (Eds.), Developmental psychology: An advanced textbook (pp. 731787). Hillsdale, NJ: Erlbaum.

Conselho Nacional de Combate à Discriminação, \& Ministério da Saúde. (2004). Brasil sem Homofobia: Programa de Combate à Violência e à Discriminação contra GLTB e de Promoção da Cidadania Homossexual. Brasília, DF: Ministério da Saúde.

DaMatta, R. (1987). A casa e a rua: Espaço, cidadania, mulher e morte no Brasil. Rio de Janeiro, RJ: Guanabara.

Demo, P. (2005). Éticas multiculturais: Sobre convivência humana possível. Petrópolis, RJ: Vozes.

Fone, B. (2000). Homophobia: A history. New York: Picador.

Gaskell, G. (2002). Entrevistas individuais e grupais. In M. W. Bauer \& G. Gaskell (Eds.), Pesquisa qualitativa com texto, imagem e som: Um manual prático (pp. 64-89). Petrópolis, RJ: Vozes.

Gould, S. J. (1991). A falsa medida do homem. São Paulo, SP: Martins Fontes.

Guzzo, R. S. L. (2003). Saúde psicológica, sucesso escolar e eficácia na escola: Desafios do novo milênio para a psicologia escolar. In Z. A. P. Del Prette (Ed.), Psicologia escolar e educacional: Saúde e qualidade de vida (pp. 25-42). Campinas, SP: Alínea.

Hall, S. (1998). A identidade cultural na pós-modernidade. Rio de Janeiro, RJ: DP\&A.

Junqueira, R. D. (2009). Homofobia nas escolas: Um problema de todos. In R. D. Junqueira (Ed.), Diversidade sexual na educação: Problematizações sobre a homofobia nas escolas (pp. 13-51). Brasília, DF: Secretaria de Educação Continuada, Alfabetização e Diversidade, Ministério da Educação.

Louro, G. L. (1998). Gênero, sexualidade e educação: Uma perspectiva pós-estruturalista. Petrópolis, RJ: Vozes.

Louro, G. L. (2004). Um corpo estranho: Ensaios sobre sexualidade e teoria queer. Belo Horizonte, MG: Autêntica. 
Madureira, A. F. A. (2000). A construção das identidades sexuais não-hegemônicas: Gênero, linguagem e constituição da subjetividade (Dissertação de mestrado, Instituto de Psicologia, Universidade de Brasília, DF, Brasil).

Madureira, A. F. A. (2007a). The psychological basis of homophobia: Cultural construction of a barrier. Integrative Psychological \& Behavioral Science, 41(3-4), 225-247. doi:10.1007/s12124007-9024-9

Madureira, A. F. A. (2007b). Homophobia as a boundary phenomenon: The dynamic dance between different tensions. Integrative Psychological \& Behavioral Science, 41(3-4), 326-342. doi:10.1007/s12124-007-9027-6

Madureira, A. F. A. (2012). Belonging to gender: Social identities, symbolic boundaries and images. In J. Valsiner (Ed.), The Oxford handbook of culture and psychology (pp. 582-601). New York: Oxford University Press.

Madureira, A. F. A., \& Branco, A. U. (2001). A pesquisa qualitativa em psicologia do desenvolvimento: Questões epistemológicas e implicações metodológicas. Temas em Psicologia, 9(1), 63-75.

Madureira, A. F. A., \& Branco, A. U. (2005). Construindo com o outro: Uma perspectiva sociocultural construtivista do desenvolvimento humano. In M. A. Dessen \& A. L. Costa Júnior (Eds.), A ciência do desenvolvimento humano: Tendências atuais e perspectivas futuras (pp. 90-109). Porto Alegre, RS: Artes Médicas.

Madureira, A. F. A., \& Branco, A. U. (2007). Identidades sexuais não-hegemônicas: Processos identitários e estratégias para lidar com o preconceito. Psicologia: Teoria e Pesquisa, 23(1), 81-90. doi:10.1590/S0102-37722007000100010

Madureira, A. F. A., \& Branco, A. U. (2012a). Diversity and inclusion as central values in the construction of a democratic world. In A. U. Branco \& J. Valsiner (Eds.), Cultural psychology of human values (pp. 195-235). Charlotte, NC: Information Age.

Madureira, A. F. A., \& Branco, A. M. C. U. A. (2012b). As raízes histórico-culturais e afetivas do preconceito e a construção de uma cultura democrática na escola. In A. U. Branco \& M. C. S. L. Oliveira (Eds.), Diversidade e cultura da paz na escola: Contribuições da perspectiva sociocultural (pp. 125-155). Porto Alegre, RS: Mediação.
Moreira, A. F. B., \& Câmara, M. J. (2008). Reflexões sobre currículo e identidade: Implicações para a prática pedagógica. In A. F. Moreira \& V. M. Candau (Eds.), Multiculturalismo: Diferenças culturais e práticas pedagógicas (pp. 38-66). Petrópolis, RJ: Vozes.

Parker, R. (1991). Corpos, prazeres e paixões: A cultura sexual no Brasil contemporâneo. São Paulo, SP: Best Seller.

Ratner, C. (2002). Cultural psychology: Theory and method. New York: Kluwer.

Rogoff, B. (2003). The cultural nature of human development. New York: University Press.

Secretaria de Educação Fundamental. (1998). Parâmetros Curriculares Nacionais - Temas Transversais: $5^{a}$ a $8^{a}$ séries. Brasília, DF: Autor.

Spink, M. J., \& Medrado, B. (1999). Produção de sentido no cotidiano: Uma abordagem teórico-metodológica para análise das práticas discursivas. In M. J. Spink (Ed.), Práticas discursivas e produção de sentidos no cotidiano: Aproximações teóricas e metodológicas (pp. 41-61). São Paulo, SP: Cortez.

Vainfas, R. (2010). Trópico dos pecados: Moral, sexualidade e inquisição no Brasil. Rio de Janeiro, RJ: Civilização Brasileira.

Valsiner, J. (2007). Culture in minds and societies: Foundations of cultural psychology. New Delhi, India: Sage.

Valsiner, J., \& Rosa, A. (2007). Contemporary sociocultural research: Uniting culture, society and psychology. In J. Valsiner \& A. Rosa (Eds.), The Cambridge handbook of sociocultural psychology (pp. 1-20). New York: Cambridge University Press.

Welzer-Lang, D. (2001). A construção do masculino: Dominação das mulheres e homofobia. Revista Estudos Feministas, 9(2), 460-482. doi:10.1590/ S0104-026X2001000200008

Woodward, K. (2000). Identidade e diferença: Uma introdução conceitual. In T. T. Silva (Ed.), Identidade e diferença: A perspectiva dos estudos culturais (pp. 7-72). Petrópolis, RJ: Vozes. 